\title{
Lupus podocytopathy complicated with multiple organ injuries in a patient with severe lupus
}

\author{
Jianhong Wu, Fanxin Zeng, Xuejun Jiang, Tingting Wang, Chaoqiong Yao \\ Division of Rheumatology \& Immunology, Dazhou Central Hospital, Dazhou 635005, China \\ Correspondence to: Jianhong Wu, Chief Physician, Professor, The 13th Academic and Technical Leader of Health Committee (Sichuan Province, \\ China), Director, Division of Rheumatology \& Immunology, Dazhou Central Hospital, Dazhou 635005, China. Email: wjh8712@163.com.
}

\begin{abstract}
To investigate the clinical manifestations, pathological features, treatment, and prognosis of a special type of podocytopathy in patients with lupus nephritis (LN). The clinical data, including clinical manifestations, pathological features, immunological markers, treatment, and prognosis of one patient with lupus podocytopathy (LP), were retrospectively analyzed. Relevant literature was also reviewed. The patient was clinically diagnosed with a rare type of LP-based on medical history, clinical manifestations, laboratory tests, renal biopsy results, and relevant literature. After treatment with steroids combined immunosuppressive agents, the clinical symptoms were improved, and the nephropathy was completely reversed. The disease condition was stable during follow-up. LP is a specific pathological change in the spectrum of LN, with nephrotic syndrome (NS) as its primary clinical manifestation. Patients may also have severe lupus-associated injuries affecting multiple systems. Immunosuppressive agents combined with steroids can improve clinical symptoms.
\end{abstract}

Keywords: Lupus podocytopathy (LP); lupus nephritis (LN); case presentation

Submitted Jul 29, 2019. Accepted for publication Aug 12, 2019.

doi: 10.21037/apm.2019.09.02

View this article at: http://dx.doi.org/10.21037/apm.2019.09.02

\section{Introduction}

Lupus podocytopathy (LP) is a special subtype of lupus nephritis (LN) discovered in recent years, with a reported incidence of $<2 \%$ in foreign literature (1). To our knowledge, few pieces of Chinese literature have described this condition. In this article, we reported one case of LP diagnosed in our center.

\section{Case presentation}

A 23-year-old married woman was admitted to our center on 8 November 2018 due to fatigue and shortness of breath for 1 month and syncope and limb convulsions for more than 10 days. She began to experience fatigue and shortness of breath after exercise at the beginning of October 2018 and developed chills and fever (peak body temperature: $39^{\circ} \mathrm{C}$ ) after October 20 . The condition was diagnosed as a common cold in a local clinic, and her fever disappeared after treatment with nonsteroidal antiinflammatory drugs (NSAIDs) and antibiotics. On October 22, she experienced an episode of syncope and woke up about 2 min later. On the evening of October 23, she suffered from one episode of limb spasticity, foaming at the mouth, clenching of the teeth, loss of consciousness, and upward-looking of both eyes, which were relieved after a few min. On October 24, she was admitted to the emergency department of a tertiary hospital in Hainan Province. Physical examination at admission showed her blood pressure (BP) was $78 / 44 \mathrm{mmHg}$, and her heart rate was 49 times/min. Electrocardiogram revealed the presence of third-degree atrioventricular block. A routine blood test showed the white blood cell count was $26.82 \times 10^{9} / \mathrm{L}$, the neutrophil percentage was $82.3 \%$, and the hemoglobin level was $91 \mathrm{~g} / \mathrm{L}$. Testing for cardiac enzymes and biomarkers showed aspartate aminotransferase (AST) 6,696.2 U/L, creatinekinase (CK) $862 \mathrm{U} / \mathrm{L}$, lactate dehydrogenase (LDH) 
10,066.7 U/L, and $\alpha$-hydroxybutyrate dehydrogenase (HBD) 3,974.5 U/L. The possibility of "acute fulminant myocarditis" was considered. After intra-aortic balloon counter pulsation, insertion of a temporary pacemaker, and administration of vasoactive drugs, the $\mathrm{BP}$, and heart rate were maintained stable. Further tests were performed. Routine urinalysis showed protein +4 , occult blood +3 , and urine urobilinogen $+/-$. Testing for myocardial markers showed the high-sensitivity troponin $\mathrm{T}$ was $5.64 \mathrm{ug} / \mathrm{L}$. Testing for liver and kidney functions showed albumin $30.7 \mathrm{~g} / \mathrm{L}$, serum creatinine $164 \mu \mathrm{mol} / \mathrm{L}$, and blood uric acid level $703 \mu \mathrm{mol} / \mathrm{L}$. Electrolyte tests showed potassium $5.59 \mathrm{mmol} / \mathrm{L}$ and sodium $129.7 \mathrm{mmol} / \mathrm{L}$. Testing for the biochemical markers of acute pancreatitis showed blood amylase 352.1 U/L, pancreatic amylase 317.3 U/L, and pancreatic lipase $399.1 \mathrm{U} / \mathrm{L}$. Testing of autoantibodies showed antinuclear antibody (ANA) titer 1:1,000, antidouble-stranded DNA (anti-dsDNA) antibodies $12.0 \mathrm{IU} / \mathrm{mL}$, and anti-SS-A $60+$ +-. Coomb test showed a negative result. Complement tests showed C3 $0.34 \mathrm{~g} / \mathrm{L}$ and C4 $0.066 \mathrm{~g} / \mathrm{L}$. On October 27, facial erythema began to appear, along with gradually worsened facial and lower extremity edema. The diagnoses at admission were: (I) acute fulminant myocarditis; third-degree atrioventricular block; and cardiogenic shock; (II) systemic lupus erythematosus accompanied by multisystem injuries; (III) acute pancreatitis. Treatments were as follows: intravenous bolus injection of methylprednisolone (MP) $200 \mathrm{mg}$ was applied for 1 day, $500 \mathrm{mg}$ for 1 day, and then maintained at $80 \mathrm{mg} / \mathrm{d}$, along with intravenous gamma globulin pulse therapy, hemofiltration, and plasma exchange $(2,500 \mathrm{~mL}$ in total). After the above treatment, facial erythema subsided, although the edema persisted. After the vital signs became stable, the temporary pacemaker was withdrawn. The patient was then transferred back to our hospital.

Her personal and family medical histories had no particular record. She had four pregnancies, which included one successful delivery, one induction of labor, and two stillbirths.

Physical examination showed body temperature (T) $36.6{ }^{\circ} \mathrm{C}$, pulse $(\mathrm{P}) 92$ beats/min, respiratory rate $(\mathrm{R})$ 18 breaths/min, and BP $124 / 68 \mathrm{mmHg}$. She was conscious but had the appearance of severe anemia, without yellowing of the eyes and skin. Severe edema was observed to affect the face and lower extremities. No superficial lymph node enlargement was palpable. During the cardiopulmonary examination, the dull sound was examined by percussion, and the breath sounds were decreased in both lower lungs.
Physical examination of the heart showed no obvious abnormality. Abdominal examination showed abdominal bloating, mild tenderness and rebound tenderness in the upper abdomen, and shifting dullness (+). Neurological examination showed grade 5 limb muscle-strength, normal muscle tone, normal physiological reflex, and negative pathological features.

During the auxiliary examinations, routine blood tests showed white blood cell count $8.37 \times 10^{9} / \mathrm{L}$, neutrophil proportion $92.4 \%$, red blood cell count $1.9 \times 10^{12} / \mathrm{L}$, hemoglobin $48 \mathrm{~g} / \mathrm{L}$, and platelet count $51 \times 10^{9} / \mathrm{L}$. Blood biochemistry showed urea nitrogen $37.92 \mathrm{mmol} / \mathrm{L}$, serum creatinine $744.9 \mu \mathrm{mol} / \mathrm{L}$, blood uric acid $560 \mu \mathrm{mol} / \mathrm{L}$, sodium $132.9 \mathrm{mmol} / \mathrm{L}$, chlorine $94.0 \mathrm{mmol} / \mathrm{L}$, creatine kinase $92 \mathrm{U} / \mathrm{L}, \mathrm{CK}-\mathrm{MB}$ isoenzyme $26 \mathrm{U} / \mathrm{L}, \mathrm{HBD} 335 \mathrm{U} / \mathrm{L}$; and $\mathrm{LDH} 391 \mathrm{U} / \mathrm{L}$. Testing for pancreatic function showed blood amylase $158.7 \mathrm{U} / \mathrm{L}$, blood pancreatic amylase 743.2 U/L, and pancreatic lipase 202.0 U/L. Analysis of myocardial markers showed troponin $0.151 \mu \mathrm{g} / \mathrm{L}$ and myoglobin $136.1 \mu \mathrm{g} / \mathrm{L}$. Blood gas analysis showed $\mathrm{pH}$ 7.418, $\left(\mathrm{PCO}_{2}\right) 29.6 \mathrm{mmHg}$, and $\left(\mathrm{HCO}_{3}\right.$-std) $20.8 \mathrm{mmol} / \mathrm{L}$. ECG findings were marginally normal. Fasting blood biochemistry showed albumin $30.88 \mathrm{~g} / \mathrm{L}$ and triglyceride $2.19 \mathrm{mmol} / \mathrm{L}$. Urinalysis showed urine protein + and urine occult blood $3+$. The result of $24 \mathrm{~h}$ urine protein quantitation was $327 \mathrm{mg}$. Testing for inflammatory markers showed erythrocyte sedimentation rate $27 \mathrm{~mm} / \mathrm{h}$, C-reactive protein $1.9 \mathrm{mg} / \mathrm{L}$, and procalcitonin $0.42 \mathrm{ng} / \mathrm{mL}$. Testing for coagulation function showed D-dimer $2,625 \mathrm{ng} / \mathrm{mL}$ and fibrin and fibrinogen degradation products $18.02 \mu \mathrm{g} / \mathrm{mL}$. Brain natriuretic peptide precursor level was $20,457 \mathrm{pg} / \mathrm{mL}$. Testing for antiviral antibodies showed rubella virus-specific IgG antibodies $83 \mathrm{IU} / \mathrm{mL}$, cytomegalovirusspecific IgG antibodies $106 \mathrm{U} / \mathrm{mL}$, herpes simplex virusspecific IgG antibodies $83 \mathrm{IU} / \mathrm{mL}$, and complements 3 (C3) $0.590 \mathrm{~g} / \mathrm{L}$ and $\mathrm{C} 40.113 \mathrm{~g} / \mathrm{L}$. Testing for autoantibodies showed: ANA, 1:100 speckled pattern; anti-SSA/60 (+/-); AECA (+); Coomb's test (-); MPO (-); PR3 (-); GBM $(-)$; ACL $(-)$; $\beta 2 \mathrm{GP} 1(-)$; LA (-); and aPS/aPT (-). The ADAMTS13 activity assay showed a negative result. There was no abnormality in the peripheral blood smear. Bone marrow cytology indicated proliferative anemia.

Chest and abdomen CT revealed patchy densities in the lower lobes of both lungs, suggesting the presence of inflammatory changes, and bilateral pleural effusion was detected. Additionally, anemia-associated heart changes were found, the pancreas was full, the spleen was full, with decreased density, peritoneal effusion was detected, 
and parts of the omentum, mesangium, and fascia became thickened. Also, subcutaneous edema was seen in bilateral thoracic and abdominal areas. Abdominal color Doppler measured $5.1 \mathrm{~mL}$ of fluid in the peritoneal cavity, along with contrast-enhanced signals in both kidneys.

The diagnoses at admission included: (I) systemic lupus erythematosus: LN, acute renal failure, lupus-associated acute myocarditis, lupus-associated acute pancreatitis, lupus encephalopathy, lupus-associated blood system injuries; (II) electrolyte disorders; (III) metabolic acidosis.

Diagnosis and treatment: After intravenous administration of MP $80 \mathrm{mg} / \mathrm{d}$ for 12 consecutive days (from November 02-08, 2018), the dose was reduced to $60 \mathrm{mg} / \mathrm{d}$ for 10 days (November 21-30) and then $40 \mathrm{mg} / \mathrm{d}$ for maintenance. Cyclophosphamide (CTX) $0.2 \mathrm{~g}$ was intravenously used every two days (November 10-18; in total $1.0 \mathrm{~g}$ ). Low-molecular-weight heparin 2,5005,000 IU was subcutaneously injected once daily. Alfacalcidol, calcium tablets, lansoprazole, and cyclosporine $75 \mathrm{mg}$ were orally administered twice daily after CTX was discontinued. Red blood cells $2 \mathrm{U}$ were infused. The results of subsequent examinations performed on December 03, 2018, were as follows: routine blood test showed $\mathrm{Hb}$ $80 \mathrm{~g} / \mathrm{L}$. Urinalysis showed both protein and occult blood were negative. Blood biochemistry showed serum creatinine $116.2 \mu \mathrm{mol} / \mathrm{L}$, urea nitrogen $10.24 \mathrm{mmol} / \mathrm{L}$, alanine aminotransferase $88 \mathrm{U} / \mathrm{L}, \gamma$-glutamyl transpeptidase $44 \mathrm{U} / \mathrm{L}$, albumin $41.3 \mathrm{~g} / \mathrm{L}, \mathrm{CK}-\mathrm{MB}$ isoenzyme $7 \mathrm{U} / \mathrm{L}, \mathrm{LDH}$ 294 U/L; HBD 205 U/L, blood amylase 189 U/L, pancreatic amylase 122.0 U/L, and lipase $155.7 \mathrm{U} / \mathrm{L}$. Testing for coagulation function showed the levels of D-dimer, fibrin, and fibrinogen degradation products were normal. The level of brain natriuretic peptide precursor was $493.9 \mathrm{pg} / \mathrm{mL}$. Renal biopsy was performed on November 21, 2018, to identify the pathological type, and the pathological findings (Figures 1-3) met the diagnostic criteria of acute tubular injury. No immunocomplex deposit was found, which did not support a diagnosis of immunocomplexmediated glomerulus nephritis. No apparent thickening of the glomerular basement membrane was observed under electron microscopy. The foot processes of the podocytes showed segmental fusion. No definite electron-dense deposit was found. A pathological diagnosis of LP was finally made. (No diffuse fusion of the foot processes of the podocytes was found under an electron microscope, which might be a result of the treatments for LP).

\section{Discussion}

The clinical manifestations of $\mathrm{LN}$ depend on its pathological types. LN patients with proteinuria tend to have subendothelial and epithelial immunocomplex deposits near the glomerular capillary loops, with the typical pathological types being types III, VI, V, or V + III/ VI (2). However, recent studies have found that a small number of LN patients with clinical manifestations of nephrotic syndrome (NS) have similar minor lesions on renal pathology; while immunocomplex deposits may be present (or absent) only in the mesangial area under light microscopy, the foot processes of the podocytes are found to be massively fused under electron microscopy. Since these patients are responsive to hormone therapy, clinical and epidemiological evidence have demonstrated that podocyte dysfunction is associated with SLE (3-7). Some authors have defined this specific pathological type as LP, which has special clinical-pathological manifestations, treatment response, and prognosis (7).

The patient reported in this article had multiple organ injuries (including injuries in neurological system and circulation, multi-serous effusion, and NS) and other manifestations including facial erythema and positive anti-nuclear antibody/anti-ds-DNA antibody, which met the diagnostic criteria of SLE released by American Rheumatism Association (ARA) in 1982. However, pathology showed segmental fusion (rather than diffuse fusion) of glomerular podocytes. Such an atypical pathological change of podocytes might be explained by steroid use and plasma exchange. The patient had severe renal injury, with NS and acute kidney injury (AKI, which is defined by the phenomenon that SCr rises by $\geq 26.5 \mu \mathrm{mol} / \mathrm{L}$ or exceeds $50 \%$ of the baseline value within 48 hour) as the primary clinical manifestations, although light microscopy, immunofluorescence, and electron microscopy did not find immunocomplex deposits in the kidneys. Only the podocyte injury was discovered. Although the pathological manifestations of glomerular injury were mild, the acute tubulointerstitial injury was severe. Patients with concurrent AKI are reported to have a severe acute tubulointerstitial injury or acute tubular necrosis (7), suggesting that in addition to the manifestations of NS, the occurrence of AKI is associated with the tubulointerstitial injury.

According to the literature (8-10), the most common manifestation of LP is blood system involvement, followed 

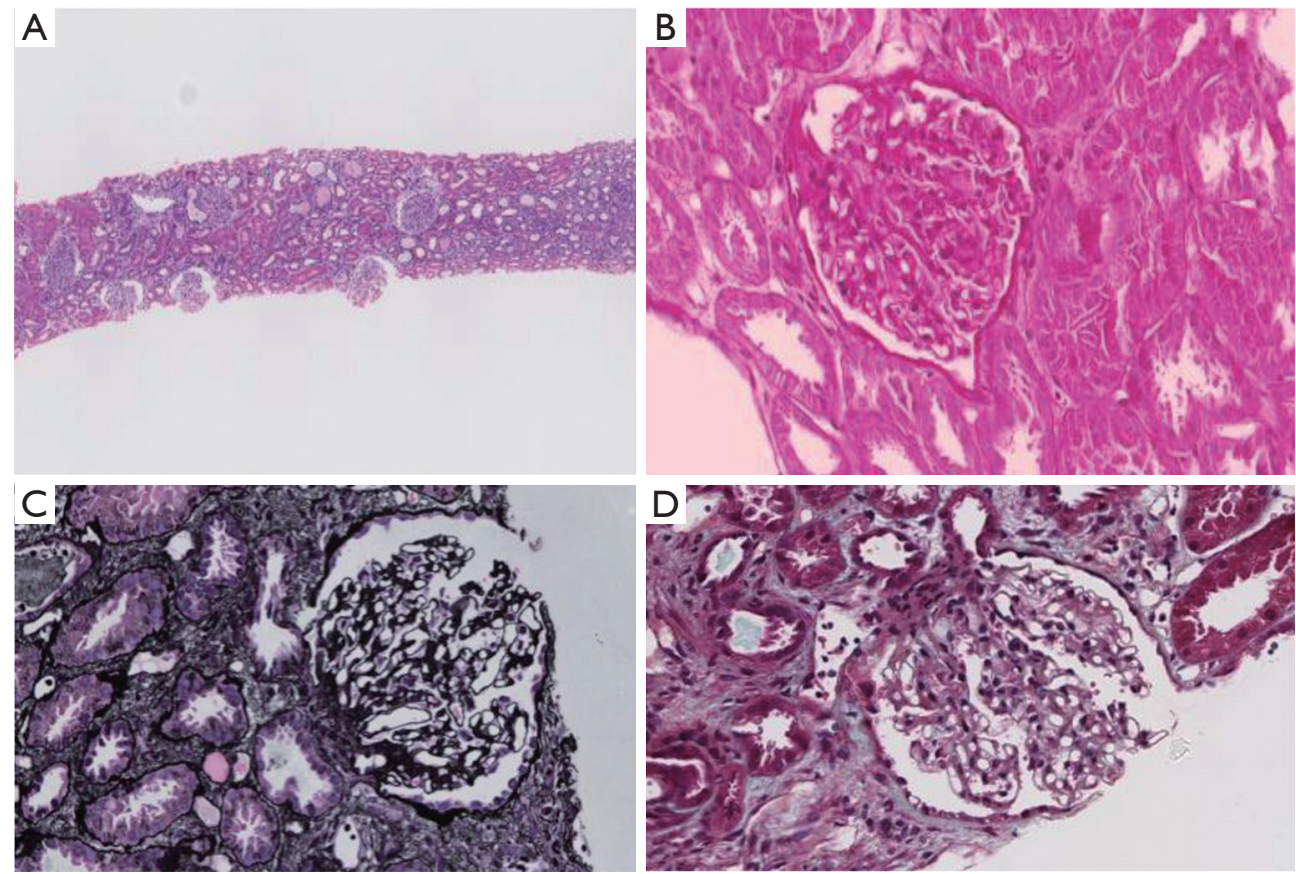

Figure 1 Light microscopy: the specimen (mainly renal cortex) underwent (A) HE, ×40; (B) PAS, ×200; (C) PASM, ×200; and (D) Masson, $\times 200$ staining. Eight glomeruli were visible, and no glomerular sclerosis was observed. Injuries in other glomeruli were mild. No apparent proliferation of mesangial cells or stromal hyperplasia was found. There was no obvious mesophilic deposition in the mesangial area. The capillary loops opened well. The basement membrane was not thickened, without visible nail-like structure, mesangial insertion, or doubletrack sign. No proliferation of parietal epithelial cells was observed; neither was a crescent sign. Granular degeneration of renal tubular epithelial cells was found, along with many hemoglobin casts, partial tubular dilatation, flat epithelial cells, and disappearance of brush border; shedding of a few epithelial cells, renal interstitial edema, and infiltration of a small number of inflammatory cells were found. The fibrosis was not obvious. The wall of the small arteries was thickened, and the lumens were narrow.

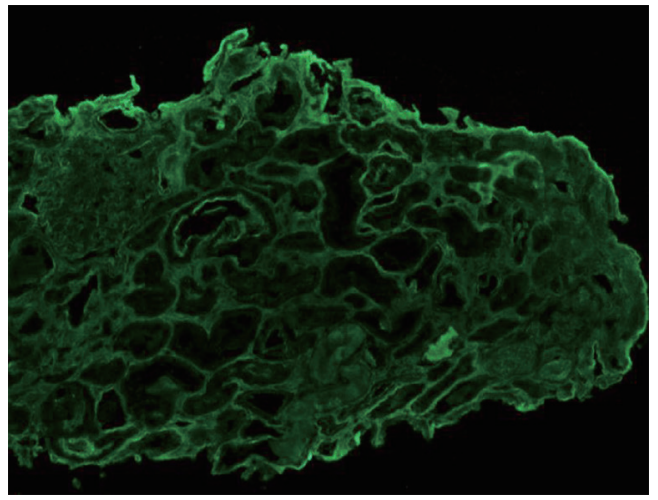

Figure 2 Immunofluorescence assay. The results were: $\operatorname{IgG}(-)$, $\operatorname{IgA}(-), \operatorname{IgM}(+/-)$, C3 (-), C1q (-), Fib (-), and ALB (+) (absorbable drops seen in renal tubules). by facial erythema and joint pain. Laboratory tests often indicate a high positive rate of ANA, followed by antiribosomal $\mathrm{P}$ protein antibodies; the positive rates of anti-Sm, ds-DNA, SSA, and SSB antibodies are relatively low. In a relatively large-scale clinical study on podocytopathy, Wang et al. reported $108 \mathrm{LN}$ patients (28 cases in podocytopathy group and 80 cases in mesangial hyperplasia group) who underwent renal biopsy, which showed the extracorporeal clinical manifestations of podocytopathy group were better than mesangial hyperplasia group; in addition, no multi-systemic involvement or severe manifestations of lupus was noted (11). In our current case, in contrast, the patient experienced rapid disease onset and progression, along with multiple severe extrarenal manifestations. The 

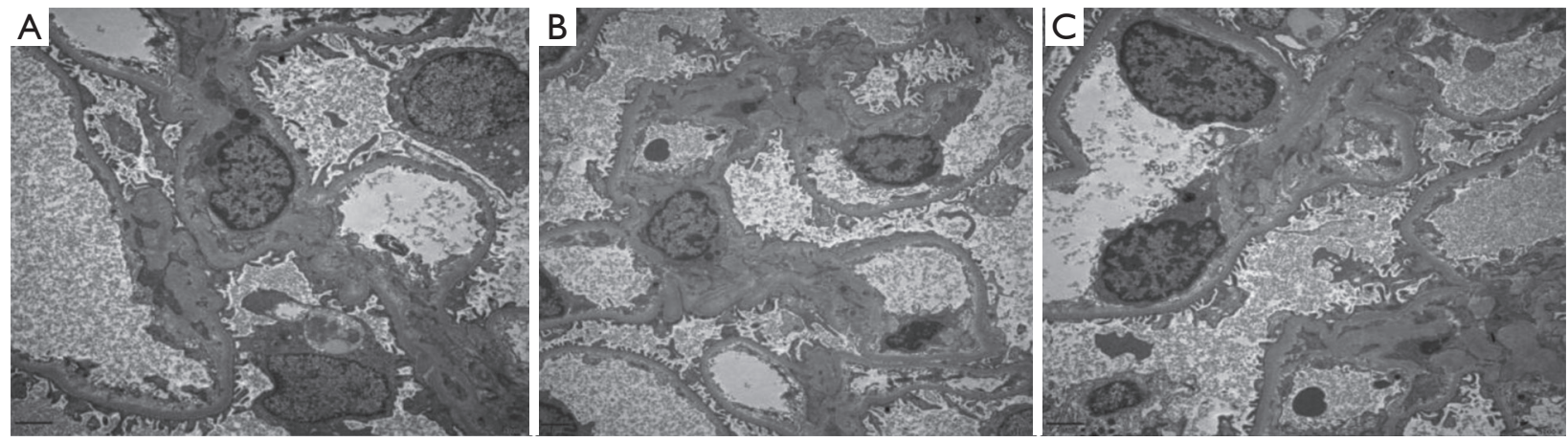

Figure 3 Electron microscopy. One glomerulus was detected under the microscope. The vacuolar degeneration of the capillary endothelial cells was evident. Red blood cells were visible in a few lumens. No obvious proliferation of endothelial cells was found, and the capillary loops opened well. There was no obvious thickening of the renal parietal layer; the parietal cells showed vacuolar degeneration did not proliferate. Basement membrane showed no obvious thickening (about 230-380 nm in thickness), and segmental shrinkage was observed. The visceral epithelial cells became swollen and showed vacuolar degeneration. The foot processes of the podocytes showed segmental fusion. The proliferation of the mesangial cells and stromal hyperplasia were visible in the mesangial area, but no definite electron-dense deposits were observed. Vacuolar degeneration of renal tubular epithelial cells was observed, along with shedding of a small number of renal tubular epithelial cells and infiltration of a small number of inflammatory cells in renal interstitium. Red blood cells accumulated in the lumens of a few capillaries. Uranyl acetate and lead citrate staining, (A) ×5,000; (B) $\times 4,000 ;(\mathrm{C}) \times 5,000$.

underlying reason was unclear. Studies on the treatment of podocytopathy have shown that calcineurin inhibitors (CNI) are effective in repairing damaged podocytes and may also be applied in the treatment of LP (12). In our current case, the patient was treated with steroids and CTX first, followed by cyclosporine and other drugs. Her renal function was completely reversed, and the clinical manifestations were improved. She received regular followup visits after discharge, during which the disease condition was stable.

\section{Conclusions}

In summary, the clinical manifestations of LP differ among individual patients. A better understanding of the clinical stages of LP and a tailored treatment protocol is particularly important to improve prognosis in these patients.

\section{Acknowledgments}

None.

\section{Footnote}

Conflicts of Interest: The authors have no conflicts of interest to declare.

Etbical Statement: The authors are accountable for all aspects of the work in ensuring that questions related to the accuracy or integrity of any part of the work are appropriately investigated and resolved. Oral informed consent was obtained from the patient for publication of this case report and any accompanying images.

\section{References}

1. Huong DL, Papo T, Beaufils H, et al. Renal involvement in systemic lupus erythematosus. A study of 180 patients from a single center. Medicine (Baltimore) 1999;78:148-66.

2. Hu WX, Liu CB, Sun HO, et al. Clinical and immunological features of 1352 Chinese patients with lupus nephritis. Chinese Journal of Nephrology Dialysis \& Transplantation 2006;15:401-8,442.

3. Wang YT, Chou HH, Chen FF, et al. A case of minimal-change nephrotic syndrome in pediatric lupus erythematosus: just a coincidence? Lupus 2006;15:244-7.

4. Hertig A, Droz D, Lesavre P, et al. SLE and idiopathic nephrotic syndrome: coincidence or not? Am J Kidney Dis 2002;40:1179-84. 
5. Hickman PL, Nolph KD, Jacobs R, et al. Idiopathic focal segmental glomerulosclerosis in a patients with systemic lupus erythematosus: an unusual combination. Am J Kidney Dis 1994;23:582-6.

6. Kraft SW, Schwartz MM, Korbet SM, et al. Glomerular podocytopathy in patients with systemic lupus erythematosus. J Am Soc Nephrol 2005;16:175-9.

7. Hu W, Chen Y, Wang S, et al. Clinical-morphological features and outcomes of lupus podocytopathy. Clin J Am Soc Nephrol 2016;11:585-92.

8. Bomback AS, Markowitz GS. Lupus Podocytopathy: A Distinct Entity. Clin J Am Soc Nephrol 2016;11:547-8.

9. Wang SF, Chen H, Chen YH, et al. Clinic-pathological characteristics and outcomes of patients with lupus

Cite this article as: $\mathrm{Wu} \mathrm{J}$, Zeng F, Jiang $\mathrm{X}$, Wang T, Yao C. Lupus podocytopathy complicated with multiple organ injuries in a patient with severe lupus. Ann Palliat Med 2019;8(5):763-768. doi: 10.21037/apm.2019.09.02 podocytopathies. J Nephrol Dialy Transplant 2015; 24:301-6.

10. Han TS, Schwartz MM, Lewis EJ. Association of glomerular podocytopathy and nephrotic proteinuria in mesangial lupus nephritis. Lupus 2006;15:71-5.

11. Wang SF, Chen YH, Chen DQ, et al. Clinic-pathological research of lupus podocytopathy with mesangial proliferation. Chinese Journal of Nephrology, Dialysis \& Transplantation 2016;25:507-12.

12. Liu $\mathrm{ZH}, \mathrm{Wu} \mathrm{Q}$, Tang $\mathrm{X}$, et al. Detection of calcineurin expression in podocyte in patients with membranous nephropathy. Chinese Journal of Nephrology,Dialysis \& Transplantation 2010;19:3-11. 